\title{
COMPARANDO OS RESULTADOS DO ENADE 2009 POR \\ NÚMERO DE INSTITUIÇÕES E NÚMERO DE ESTUDANTES: \\ COMO ANDA O DESEMPENHO ACADÊMICO DOS \\ CURSOS DE ADMINISTRAÇÃO?
}

\author{
COMPARING 2009 ENADE RESULTS BY NUMBER OF \\ BUSINESS SCHOOLS AND STUDENTS: \\ HOW ARE UNDERGRADUATE MANAGEMENT COURSES \\ PERFORMING?
}

\section{ALEXANDRE MENDES NICOLINI alexandre.nicolini@unigranrio.com.br RUI OTÁVIO BERNARDES DE ANDRADE \\ ADRIANA AMADEU GARCIA TORRES

\author{
UNIVERSIDADE DO GRANDE RIO
}

\begin{abstract}
RESUMO
O objetivo deste artigo é comparar o desempenho acadêmico de universidades, centros universitários e faculdades, públicas e privadas, por tipo de instituição de ensino superior e pelo número de estudantes nelas matriculados, com base na performance dos seus egressos. Para tanto, a pesquisa analisou e categorizou os microdados gerados pelo Exame Nacional de Desempenho (Enade) de 2009, realizado pelo INEP, valendose dos documentos oficiais e dos artigos sobre o tema para descrever e explicar os resultados do processo avaliativo. As conclusões mostraram que universidades são melhores que centros universitários e faculdades, que instituições públicas não são sempre as melhores, e que o crescimento do número de estudantes em universidades particulares promete impactos positivos no desempenho dos profissionais que ingressarão no mercado de trabalho.
\end{abstract}

Palavras-chave: avaliação; universidade; curso de Administração

\section{ABSTRACT}

The aim of this paper is to compare universities, colleges and others forms of business schools in Brazil, verifying their academic performance by public and private institutions and their number of undergraduate students, based on the performance of its graduates. The research describes the scenery of higher education evaluation and tries to explain the results and its impacts, using official documents, literature on the theme and a database provided by INEP - a government institution in charge of testing Brazilian students. Results show that universities are much better than colleges and other forms of business schools; public institutions are not always the best - the opposite of what is expected in Brazil - and the growth of students in private universities promises positive impacts in terms of the performance of future management professionals.

Keywords: evaluation; university; Management courses. 


\section{INTRODUÇÃO}

Decerto tão importante quanto a política pública é o instrumento de avaliação desta. Ciente disto, na última década e meia o Ministério da Educação buscou diferentes formas de mensurar o desempenho das Instituições de Ensino Superior (IES). Para tanto, instituiu e realizou sistematicamente a avaliação dos resultados obtidos por diversos cursos superiores em todas as áreas do conhecimento. Alguns dos instrumentos utilizados, entre os quais o Provão e o Enade, ficaram conhecidos nas suas épocas diante das polêmicas causadas e do próprio peso que assumiram ao reforçarem ou mancharem a reputação de cada IEs.

Soma-se às controvérsias o fato de que tais avaliações foram realizadas sob a égide de quatro ministros da educação que respondiam a dois partidos de orientações ideológicas diferentes, de modo que avaliar a política pública, neste caso em especial, se mostra um processo complexo, cheio de contradições e incertezas, que vai muito além dos instrumentos definidos para mensurá-lo. Ainda assim, é digno de nota o fato de as políticas adotadas para a avaliação do ensino superior guardarem surpreendente continuidade, ação esta que encorajou a confecção deste artigo.

Como objeto de estudo tem-se um dos primeiros cursos a serem avaliados: o bacharelado em administração, maior curso superior oferecido no país, tanto em número de estudantes quanto de instituições de ensino superior (IES) que o oferecem. Coloca-se como objetivo deste artigo analisar o desempenho acadêmico dos estudantes dessas escolas, comparando o resultado obtido por universidades, centros universitários ou faculdades, públicas e privadas. Não se limita, no entanto, a considerar apenas as IES, mas também seus respectivos números de estudantes, para tentar dimensionar o impacto dos desempenhos destes estudantes no universo de novos profissionais formados para o mercado de trabalho.

Para tanto, foram considerados os microdados disponibilizados pelo Instituto Nacional de Estudos e Pesquisas (INEP), referentes ao Exame Nacional de Desempenho (ENADE) de 2009. Não obstante, para compreender melhor a lógica dos exames, este trabalho valeu-se também dos documentos 
oficiais que estruturam o processo avaliativo e dos artigos e dissertações que o analisam.

Em suma, a pesquisa empreendida baseou-se em análise bibliográfica e documental, bem como na apreciação dos microdados obtidos no Enade 2009 para verificar o desempenho entre universidades, centros universitários e faculdades, públicas e privadas. Os resultados mostram que as universidades são indiscutivelmente melhores que centros universitários e faculdades, que os centros universitários ainda estão distantes da meta proposta na sua criação, que é a excelência do ensino, e que, apesar de as faculdades serem as que mais se distanciam desta meta, também guardam um bom número de exceções. Ao final, o senso comum prevalece: os melhores profissionais continuam saindo das universidades federais, como será visto. 


\section{O EXAME NACIONAL DE DESEMPENHO DOS CURSOS}

A história do Exame Nacional de Desempenho dos Cursos de graduação tem seu início com a instituição da Comissão Especial da Avaliação do Ensino Superior (CEA), "com a finalidade de analisar, oferecer subsídios, fazer recomendações, propor critérios e estratégias para a reformulação dos processos e políticas de avaliação do ensino superior e elaborar a revisão crítica dos seus instrumentos, metodologias e critérios utilizados” (SESU, 2003). Era o primeiro esforço para reformular o Exame Nacional de Cursos, proposto pelo governo Fernando Henrique Cardoso e que havia sido aplicado de 1996 a 2003.

A CEA partiu do princípio de que a educação é um direito e um bem público, sendo indissociáveis os processos avaliativos e o papel regulatório do Estado de fomentar e supervisionar o sistema de ensino superior, balizados pela qualidade, relevância social e autonomia. Só assim, garantia a comissão, seria assegurada a missão da educação superior de formar cidadãos, profissional e cientificamente competentes e, ao mesmo tempo, comprometidos com o projeto social do país.

Tais valores são consoantes com as palavras de Marinho-Araújo (2004, p.78), que entende ser necessário apreender, acompanhar, investigar e avaliar, no contexto da educação superior "a melhor forma de (...) tornarse cidadão - ético, político e, ainda, profissional competente”. Mas, sob o alerta de Sobrinho (2002), que entende que o processo não pode se resumir à quantificação do que foi aprendido, à medição da eficiência e produtividade ou à composição de um ranking. $\mathrm{O}$ foco da avaliação é acompanhar as relações socioeducativas que se constroem durante a formação dos estudantes e garantir o alto nível científico e social da formação superior destes futuros profissionais.

No documento resultante do trabalho da CEA, intitulado SINAES: Bases para uma Nova proposta da Educação Superior, a comissão formada por professores, estudantes e representantes do MEC propôs a criação do Sistema Nacional de Avaliação da Educação Superior, que viria a ser instituído pela Lei Io.86I, de 14 de abril de 2004. Entre suas finalidades, destaca-se "a melhoria da 
qualidade da educação superior, a orientação da expansão da sua oferta [e] o aumento permanente da sua eficácia institucional e efetividade acadêmica e social" (BRASIL, 2004).

De forma mais abrangente, o sinaEs se propôs a analisar as instituições, os cursos superiores e o desempenho dos estudantes, por intermédio das atividades de ensino, pesquisa e extensão desenvolvidas em cada instituição de ensino superior. Para tanto, utiliza-se da Avaliação Institucional (AI), da Avaliação das Condições de Ensino (ACE), do Censo da Educação Superior, do Cadastro da Educação Superior e do Exame Nacional de Desempenho dos Estudantes (Enade). Busca-se, assim, a consideração de todos os dados de forma integrada, de modo a constituir "mecanismos que garantam a exequibilidade do desenvolvimento do sistema e criem um novo fluxo para a avaliação superior no país" (MARINHO-ARAUJO, 2004, p.82).

Entretanto, a aprendizagem dos estudantes continua tendo um papel muito importante para a avaliação. E o Enade lançou como objetivo principal aferir a aprendizagem dos estudantes nos conteúdos programáticos compreendidos nas diretrizes curriculares do seu curso de graduação, nas habilidades que deveriam ter sido desenvolvidas para fazer face aos problemas esperados pelos futuros profissionais e nas competências para perceber e compreender temas que são conexos ao seu âmbito profissional, ligados à realidade brasileira e mundial (BRASIL, 2004, p. 3). A saber:

A Domínio das correntes teóricas e das linhas de pensamento da área de Administração;

в Pensamento estratégico, reconhecimento e definição de problemas, atuação preventiva, equacionamento de soluções, introdução de mudanças, transferência e generalização de conhecimentos e exercício, em diferentes graus de complexidade, do processo da tomada de decisão;

C Expressão e comunicação compatíveis com o exercício profissional, inclusive nos processos de negociação e nas comunicações interpessoais ou intergrupais;

D Reflexão crítica e atuação seletiva na esfera das operações das organizações; 
E Raciocínio lógico, crítico e analítico para operar com valores, metodologias e formulações quali-quantitativas, presentes nas relações formais e causais de fenômenos administrativos, expressando-se de modo crítico e criativo diante dos diferentes contextos organizacionais e sociais;

F Iniciativa, criatividade, determinação, vontade política e administrativa, vontade de aprender, abertura às mudanças e consciência da qualidade e das implicações éticas do seu exercício profissional;

G Interpretação e transferência de conhecimentos da experiência cotidiana para o ambiente de trabalho e para o campo de atuação profissional, em diferentes modelos organizacionais;

H Elaboração, implementação e consolidação de projetos em organizações;

I Consultoria em gestão e administração, elaboração de pareceres e perícias administrativas, gerenciais, organizacionais, estratégicas e operacionais.

Não se registrava, assim, nenhuma mudança significativa entre as habilidades e competências que o Provão e o Enade esperavam produzir no estudante ao final do curso de Administração. Ficaram mantidas, desde a primeira portaria que institui o instrumento avaliativo, tanto a confusão conceitual entre habilidades e competências como a proporção entre conhecimentos, habilidades e atitudes que, pelo marco teórico vigente, formam o conceito de competência.

As poucas diferenças entre o Enade e o Provão foram evidenciadas por Verhine et al (2006): mudou-se a frequência do exame, ampliada para três anos ou invés de anual; foram incluídos entre os examinados os estudantes ingressantes, aqueles que ainda estivessem cursando o primeiro ano do curso; e introduziu-se o cálculo do Indicador de Diferença dentre os Desempenhos Observado e Esperado (IDD), que visava a mensurar a aprendizagem conseguida durante o curso em contraste com as expectativas de performance dos estudantes, em face das suas condições socioeconômicas e experiências acadêmicas anteriores.

O IDD veio trazer uma visão mais completa da avaliação do aprendizado dos estudantes, ao mesmo tempo em que respondia a algumas críticas 
ao Provão: a primeira, uma queixa das IEs privadas da situação de desequilíbrio na avaliação se comparados às IEs públicas, especialmente com as universidades federais, por estas últimas selecionarem os candidatos mais preparados (BITTENCOURT et al., 2008). Ao considerar os conhecimentos prévios de cada estudante, o IDD estabeleceria uma medida mais justa de checagem do "valor agregado" entre instituições teoricamente comparáveis. A segunda, ao deslocar a nota do Enade da centralidade do processo avaliativo e, consequentemente, tornar sem sentido rankings e classificações anuais, se evitaria a ênfase da concorrência institucional, possibilitando a cooperação, inclusive entre instituições particulares (ROTHEN; NASCIUTTI, 2OII).

Consoante os novos objetivos, mudou-se a forma de avaliar. A nova prova foi composta de 40 questões: dez de Formação Geral (FG), sendo duas discursivas, e trinta denominadas como Componente Específico (CE) de cada curso a ser avaliado, sendo cinco discursivas. O cálculo da nota foi transformado num composto das notas em FG e CE de ingressantes e concluintes, caracterizando a aproximação do ENADE com o conceito de avaliação diagnóstica. Verhine, Dantas e Soares (2006) argumentam que o exame se propõe a englobar várias dimensões em seu teste [...] e dar um peso maior às competências profissionais e à formação geral, com ênfase nos temas transversais.

Outra avaliação daqueles autores se provou bem acertada: a premissa de que as instituições e cursos utilizariam seus resultados como ingrediente em um processo avaliativo institucional mais abrangente. Assim, O INEP instituiu o cálculo do Conceito Preliminar de Curso (CPC, BRASIL, 2008a) e do Índice Geral dos Cursos (IGC, BRASIL, 2008b), baseado nos dados produzidos pelo ENADE em conjunto com as outras dimensões avaliativas previstas pelo SINAES, como a Infraestrutura, o Corpo Docente e a Organização DidáticoPedagógica.

A partir de 20I2, entretanto, a orientação do INEP mudou: a nota dos ingressantes não será mais dada pelo desempenho destes estudantes na mesma prova pelo qual passavam os concluintes; ela será substituída pela nota que os ingressantes tiveram ao fazerem o Exame Nacional do Ensino Médio (eNEM). Esta mudança, no entanto, não invalida os dados anteriores, que serão apreciados neste trabalho. 


\section{A METODOLOGIA DO TRABALHO}

Seguindo a taxonomia proposta por Vergara (20II), tem-se aqui uma pesquisa, quanto aos fins: descritiva, na medida em que busca retratar o desempenho acadêmico das universidades, centros universitários ou faculdades, públicas e privadas, e o impacto gerado nos novos profissionais formados para o mercado de trabalho; e explicativa, pois um retrato pormenorizado do cenário da educação superior em Administração busca elucidar os fatores que o influenciam e os resultados alcançados por seus atores - como as vinculações administrativas e o real impacto do universo que está sendo tratado. Neste sentido, busca-se trabalhar uma "tese panorâmica", tendo o cuidado de usar o panorama como pano de fundo, para que o quadro não pareça “desfocado, incompleto ou de segunda mão” (ECO, I977, p. Io).

Por outro lado, quanto aos meios, trata-se de um estudo bibliográfico e telematizado, que são considerados "excelentes meios de formação científica quando realizada independentemente como análise teórica” (MARTINs; THEÓPHILO, 2009, p. 54). Para tanto, a análise do desempenho acadêmico de IES e estudantes teve lugar baseada em microdados primários disponibilizados pelo INEP em seu site referentes ao Enade 2009, além de fontes secundárias que consideram publicações acerca do tema.

Vale ressaltar que os microdados disponibilizados pelo INEP apresentam 40 variáveis. Mas, no intuito de trabalhar dados comparáveis aos da realidade brasileira, este artigo foca o tratamento de seis variáveis (Quadro I) para verificar o impacto das notas obtidas no universo de novos profissionais formados para o mercado de trabalho. 
Quadro 1 Variáveis e observações analisadas pelo artigo

\begin{tabular}{|ll|}
\hline Variável & Classificações \\
\hline Ano do Enade & 2009 \\
\hline Organização & $\begin{array}{l}\text { Universidade, Centro Universitário, Faculdade ou Centro de Edu- } \\
\text { cação Tecnológica }\end{array}$ \\
\hline Dependência Administrativa & Pública ou privada \\
\hline Área & Administração \\
\hline Total de participantes & Quantitativo de estudantes que fizeram a prova \\
\hline Conceito Enade Faixa & Sem Conceito (SC), 1, 2, 3, 4 ou 5 \\
\hline
\end{tabular}

O tratamento dos dados foi realizado nos meses de abril e maio de $2012 \mathrm{com}$ o apoio do software Statistical Package for the Social Sciences (SPSS), tendo os autores entrado em contato com o INEP, neste período, para compreender detalhes das classificações antes de iniciar as análises, especialmente no que tange à variável "organização".

Vale destacar ainda que se optou por desconsiderar do universo as IES que ficaram sem conceito. Procurou-se, assim, estabelecer uma base comum para as apreciações, recalculando a participação relativa de cada nota atribuída ao desempenho das escolas analisadas. Da mesma forma, os Institutos Federais de Educação Tecnológica foram retirados da análise, pois somente nove deles participaram do Enade 2009 com um total de 548 estudantes, sendo que quatro representados por I6o estudantes, não foram conceituados. Comparados ao universo, eles representavam uma amostra de apenas $0,3 \%$ dos cursos de Administração, o que foi considerado insuficiente para uma análise comparativa. 


\section{OS RESULTADOS DO CURSO DE ADMINISTRAÇÃO}

\section{DEMOGRAFIA DE INSTITUIÇÕES E ESTUDANTES}

Um dos objetivos deste trabalho é buscar uma análise que considere a representação de cada IEs no cenário avaliativo. Para tanto, além de utilizar a quantidade encontrada de universidades, centros universitários e faculdades, públicos e privados, será também considerado o número de estudantes inscritos em cada uma destas escolas superiores. Note-se que tal preocupação na separação dos dados refere-se ao fato de que está em curso um processo de fusões e aquisições que promovem uma consolidação da "indústria brasileira do ensino superior”. Assim, a menor dispersão do número de escolas cria uma situação distinta, onde determinadas IEs pertencentes a grupos consolidadores podem concentrar um grande número de formandos. Isso altera a quantidade de estudantes que receberam maiores ou menores notas, alterando o panorama do desempenho esperado do universo de profissionais colocados no mercado de trabalho. Por exemplo, na Tabela I, que mostra o quantitativo de ies e de estudantes nelas matriculados, os centros universitários representam pouco mais de ro\% do número de escolas, ao passo que congregam o equivalente a $25 \%$ dos estudantes destas. Isso prova que o grande número de faculdades não provoca impactos proporcionais no suprimento de mão de obra qualificada para o mercado de trabalho, como inicialmente seria de se supor. Ou seja, fazer a análise do desempenho dos tipos de IEs apenas pelo seu quantitativo naturalmente geraria uma distorção no cenário avaliativo.

Tabela 1 Quantidade de IES e número de estudantes inscritos no Enade 2009

\begin{tabular}{|lll|}
\hline & ENADE 2009 & \\
\hline Instituições de Ensino Superior (IES) & Número de IES & Número de estudantes \\
\hline Faculdades & 1.053 & 119.813 \\
\hline Universidades & 466 & 91.015 \\
\hline Centros Universitários & 135 & 31.539 \\
\hline Total & $\mathbf{1 . 6 5 4}$ & $\mathbf{2 4 2 . 3 6 7}$ \\
\hline
\end{tabular}


Verificando-se a importância relativa das organizações universitárias previstas pela legislação vigente no que se refere à participação no Enade 2009, é possível perceber no Gráfico i que os centros universitários passam a ter uma representação de $\mathrm{I} 3 \%$ do total de estudantes, mesmo se tratando de apenas $8 \%$ das IES. As universidades representam $38 \%$ dos estudantes, mesmo somando apenas $28 \%$ das IEs. Já as Faculdades perdem significativa representatividade quando se passa a considerar o número de estudantes ao invés do número de IES, pois decrescem de $64 \%$ para $49 \%$ em sua importância no cenário nacional.

Gráfico 1 Representatividade por tipo de Instituição de Ensino Superior

Número de IES - ENADE 2009

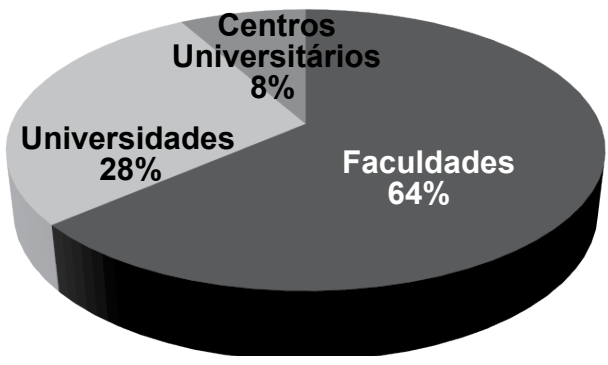

Número de estudantes- ENADE 2009

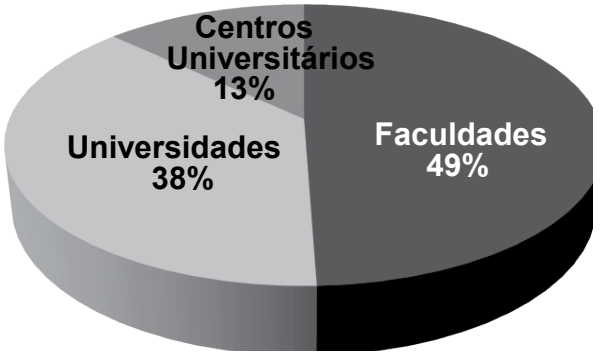

Portanto, dadas as diferenças significativas entre analisar o impacto do desempenho acadêmico dos futuros administradores por instituição e por estudantes, neste artigo se optou por trabalhar as duas formas de representação. A razão está patente: percebe-se claramente que as universidades e centros universitários já respondem por $5 \mathrm{I} \%$ dos estudantes matriculados no país, embora representem pouco mais que um terço do total de IEs em funcionamento.

\section{DIFERENCIANDO OS RESULTADOS POR IES PÚBLICAS E PRIVADAS}

$\mathrm{Na}$ análise dos microdados relativos ao ENADE 2009, percebe-se um grande número de IES sem conceito. Aproximadamente $15 \%$ das escolas (Gráfico 2) não tiveram concluintes entre os inscritos, o que quer dizer que são cursos 
novos, concentrando $5 \%$ do total de matriculados a fazer o exame naquele ano. Estas IES e estudantes não tomaram parte nos cálculos apresentados a seguir.

No Gráfico 2, cabe observar que, quinze anos depois de começado o processo avaliativo, ainda há $34 \%$ das IEs ( $32 \%$ com nota 2 e $2 \%$ com nota I) funcionando com desempenho abaixo do referencial mínimo de qualidade estipulado pelo INEP, que é determinado pela nota 3. Isso significa que, anualmente, 560 IES estão formando 85 mil administradores abaixo das expectativas, visto que habilidades básicas testadas por este exame não são sendo adequadamente desenvolvidas. Ainda que $51 \%(37 \% \mathrm{com}$ nota 3, I0\% com nota 4 e $4 \%$ com nota 5) das IES estejam numa posição considerada confortável, qualificando $60 \%$ ( $42 \%$ nota 3 , $13 \%$ nota 4 e $5 \%$ nota 5) dos estudantes dentro do padrão esperado, o maior contingente de cursos regulares e ruins está nas faculdades, o que mantém a preocupação com a qualidade do ensino diante da "proliferação de cursos vinculados a faculdades isoladas", já alertada há quinze anos atrás (CEEAD, 1997, p.25). 
Gráfico 2 Dispersão geral dos resultados

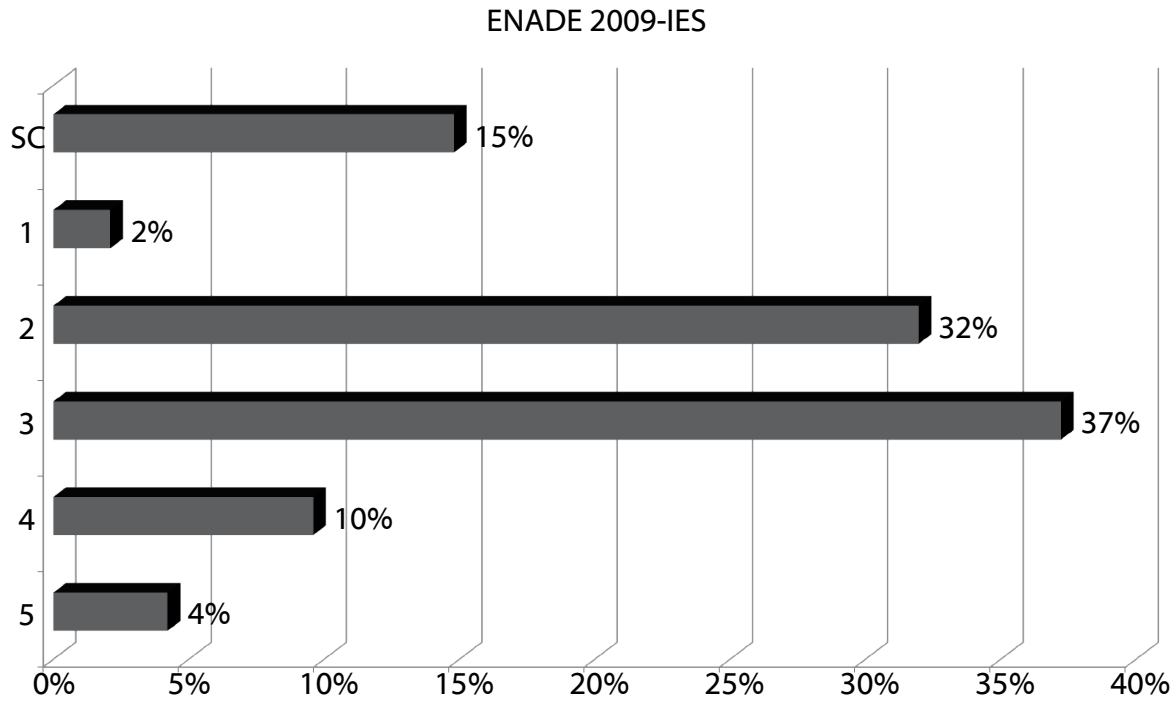

ENADE 2009 - Estudantes inscritos

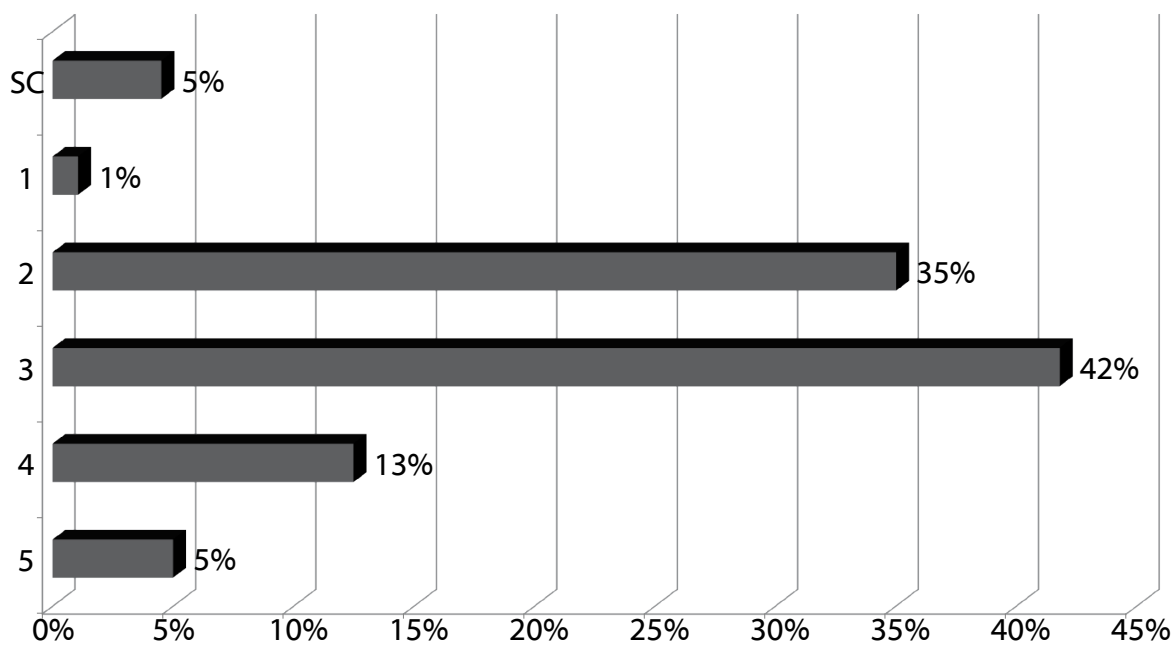


Quando se analisam os resultados do Enade decompostos por dependência administrativa das escolas examinadas (Gráfico 3), verifica-se uma dispersão das notas bem diferente ao se analisar o desempenho de iEs públicas e privadas. Há uma substancial concentração de bons resultados nas escolas públicas, que ficam positivamente distantes do padrão mínimo de qualidade. Tomando-se o somatório de IEs com notas 4 e 5, que serão consideradas neste artigo como boas e excelentes, verifica-se que as escolas públicas têm $40 \%$ (metade com nota 4 e metade com nota 5) de seu universo com desempenho bom ou excelente, ao passo que as escolas privadas têm apenas Iо\% de representantes no segmento de desempenho superior das IES, sendo somente $2 \%$ no nível de excelência. Quando se comparam somente as escolas em nível de excelência, ou seja, as com conceito 5, verifica-se que as escolas públicas têm dez vezes mais representantes que as escolas privadas $-20 \%$ contra $2 \%$.

Em contraste, as IEs privadas concentram $37 \%$ (35\% com nota 2 e $2 \%$ com nota I) dos cursos abaixo deste referencial mínimo, como se pode ver no Gráfico 3. Isso significa que o número destas abaixo do referencial mínimo de qualidade é cerca de três vezes maior do que nas públicas, onde somente I3 $\%$, (sendo $2 \%$ com nota r e II $\%$ com nota 2 ) se encontram aquém do nível satisfatório estabelecido. 
Gráfico 3 Resultados na área pública e privada por IES

ENADE 2009 - IES

IES Públicas

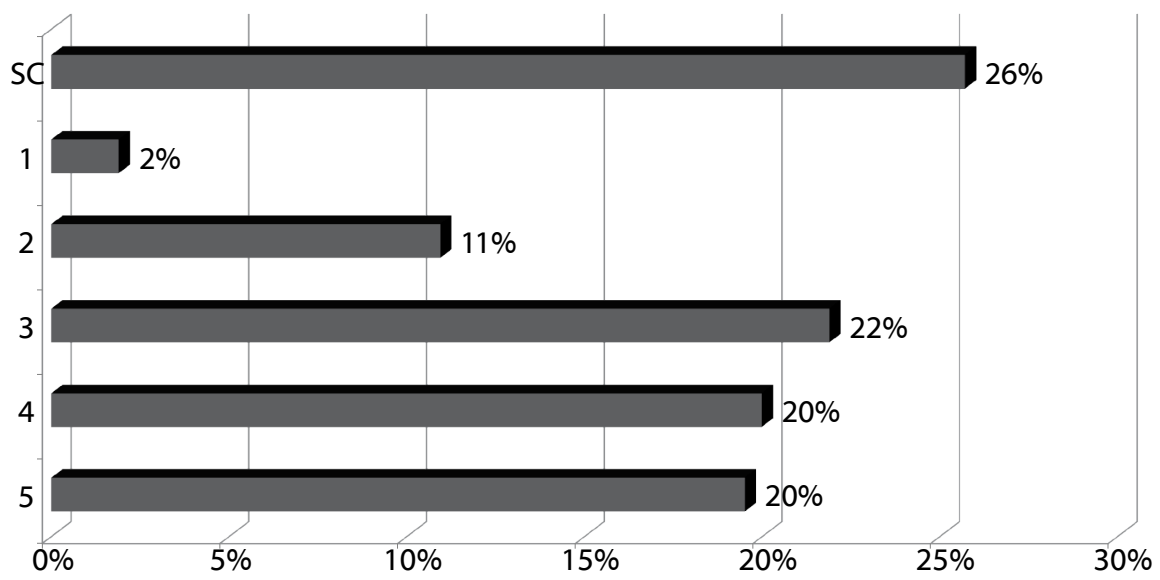

ENADE 2009 - IES

IES Privadas

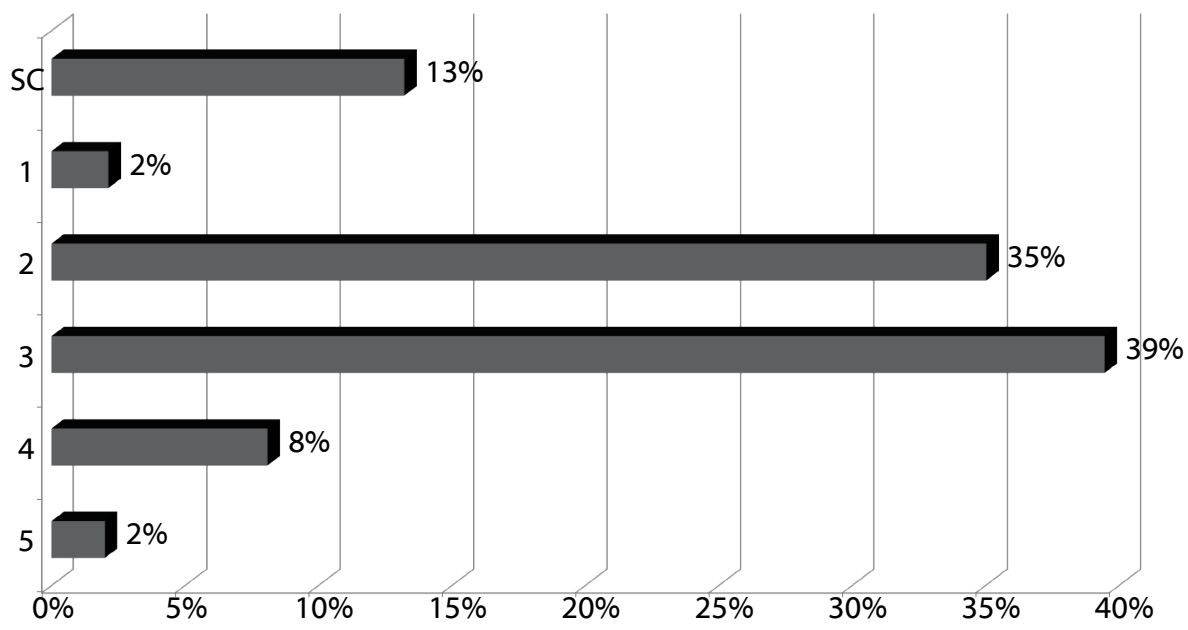


Quando se analisam os dados segundo o quantitativo de estudantes (Gráfico 4), as diferenças se mantêm. O número de estudantes de administração acima da média - ou seja, com conceitos 4 e 5 - está em $56 \%$ nas IEs públicas, sendo 31\% no nível de excelência, e em só I3\% nas IEs privadas, ou seja, há quatro vezes mais chances de obter um bom profissional nas primeiras do que nas últimas. Sem contar que, no caso das Ies privadas, somente $2 \%$ encontram-se no nível de excelência ao se considerar os estudantes inscritos no ENADE. Aliás, é instigante notar, nas instituições de ensino superior públicas, que o habitual para o estudante é ser acima da média, que os excelentes são a maioria e os bons ainda são numericamente superiores aos regulares (situados no padrão mínimo de qualidade), desenhando uma animadora curva de distribuição dos resultados que pode ser visto no Gráfico 4. No caso das IEs privadas, $38 \%$ dos estudantes estão aquém do nível satisfatório; e mesmo sendo somente I\% destes a tirar nota I, $37 \%$ é certamente um contingente muito representativo a não alcançar o mínimo de qualidade requerida. 
Gráfico 4 Resultados na área pública e privada por número de estudantes

ENADE 2009 - estudantes inscritos

IES Públicas

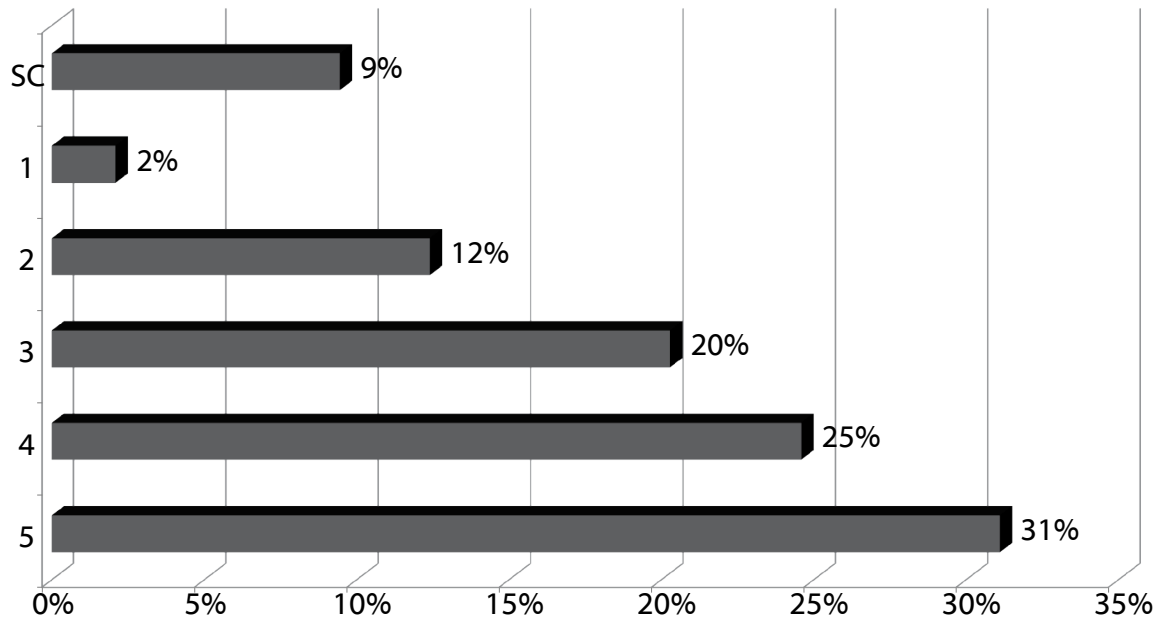

ENADE 2009 - estudantes inscritos IES Privadas

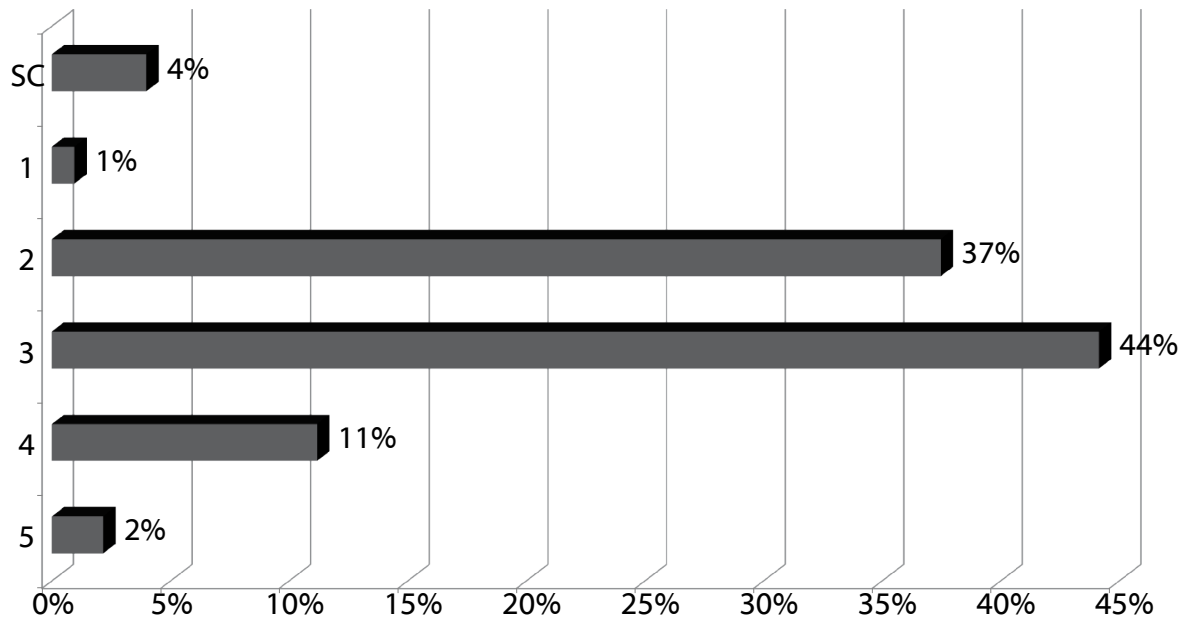


Mas como se dá a distribuição das IEs públicas e privadas por tipo de organização universitária? A Tabela 2 permite ver que, no caso da IES públicas, aproximadamente $78,9 \%$ (I72 IES) são representadas por universidades, diferente das privadas, onde aproximadamente $70,7 \%$ da amostra são representadas por faculdades - ou seja, I.022 IEs. Ao se trabalhar com o número de estudantes, a representatividade não se altera de forma significativa nas IEs públicas, onde as universidades passam a contemplar $8 \mathrm{I}, 9 \%$ da amostra. Mas o cenário é outro no caso das IEs particulares, de modo que as faculdades passam a tratar de $53,38 \%$ e não mais $70,73 \%$ do contingente. Logo, qualquer avaliação realizada neste tipo de IES passa a ter um impacto relativamente menor quando se trata do desempenho acadêmico dos bacharéis que estão sendo formados.

Tabela 2 Quantidade de IEs e número de estudantes inscritos no Enade 2009

\begin{tabular}{|c|c|c|c|c|}
\hline & $\begin{array}{l}\text { ENADE } 2009 \\
\text { Pública }\end{array}$ & & Privada & \\
\hline $\begin{array}{l}\text { Instituições } \\
\text { de Ensino } \\
\text { Superior } \\
\text { (IES) }\end{array}$ & $\begin{array}{l}\text { Número de IES / } \\
\text { Percentual }\end{array}$ & $\begin{array}{l}\text { Número de estudantes / } \\
\text { Percentual }\end{array}$ & $\begin{array}{l}\text { Número de IES / } \\
\text { Percentual }\end{array}$ & $\begin{array}{l}\text { Número de estudantes } \\
\text { / Percentual }\end{array}$ \\
\hline $\begin{array}{l}\text { Universida- } \\
\text { des }\end{array}$ & 172 / $82 \%$ & $19.615 / 83 \%$ & 294 / 20\% & $71.400 / 33 \%$ \\
\hline $\begin{array}{l}\text { Centros Uni- } \\
\text { versitários }\end{array}$ & $7 / 3 \%$ & $1.038 / 4 \%$ & $128 / 9 \%$ & $30.501 / 14 \%$ \\
\hline Faculdades & $31 / 15 \%$ & $3.100 / 13 \%$ & $1.022 / 71 \%$ & $116.713 / 53 \%$ \\
\hline Total & 210 & 23.753 & 1.444 & 218.614 \\
\hline
\end{tabular}

\section{DIFERENCIANDO OS RESULTADOS POR UNIVERSIDADES PÚBLICAS E PRIVADAS}

Verificam-se, ao analisar as universidades isoladamente nos Gráficos 5 e 6, dois tipos de comportamentos distintos. No caso das universidades públicas, mantêm-se, em linhas gerais, os mesmos bons resultados já registrados no somatório das IEs públicas. As universidades privadas, por outro lado, figuram bem melhor na avaliação que outros tipos de IES com a mesma 
dependência administrativa. Apenas $25 \%$ (24\% nota 2 e r\% nota I) dos cursos de administração oferecidos por universidades privadas encontramse abaixo dos padrões mínimos de qualidade, índice I2 pontos percentuais abaixo do setor privado como um todo, onde se tem $35 \%$ com nota 2 e $2 \%$ com nota I, e I7 pontos percentuais abaixo das faculdades privadas, onde se tem $39 \%$ com nota 2 e 3\% com nota I (Gráfico 9).

Embora neste tipo de organização se diminua a diferença entre os setores públicos e privados, há que se ressaltar ainda uma grande distância entre estas dependências administrativas. Isto ocorre porque a maioria das universidades privadas está apenas dentro do referencial mínimo de qualidade. Acima deste patamar, estão apenas $19 \%$ das universidades privadas, sendo $2 \%$ em nível de excelência e $17 \%$ num nível bom, contra $47 \%$ das universidades públicas, onde $23 \%$ têm excelência e $24 \%$ apresentam um bom nível. 
Gráfico 5 Resultados por universidades públicas e privadas

ENADE 2009 - IES

Universidades Públicas

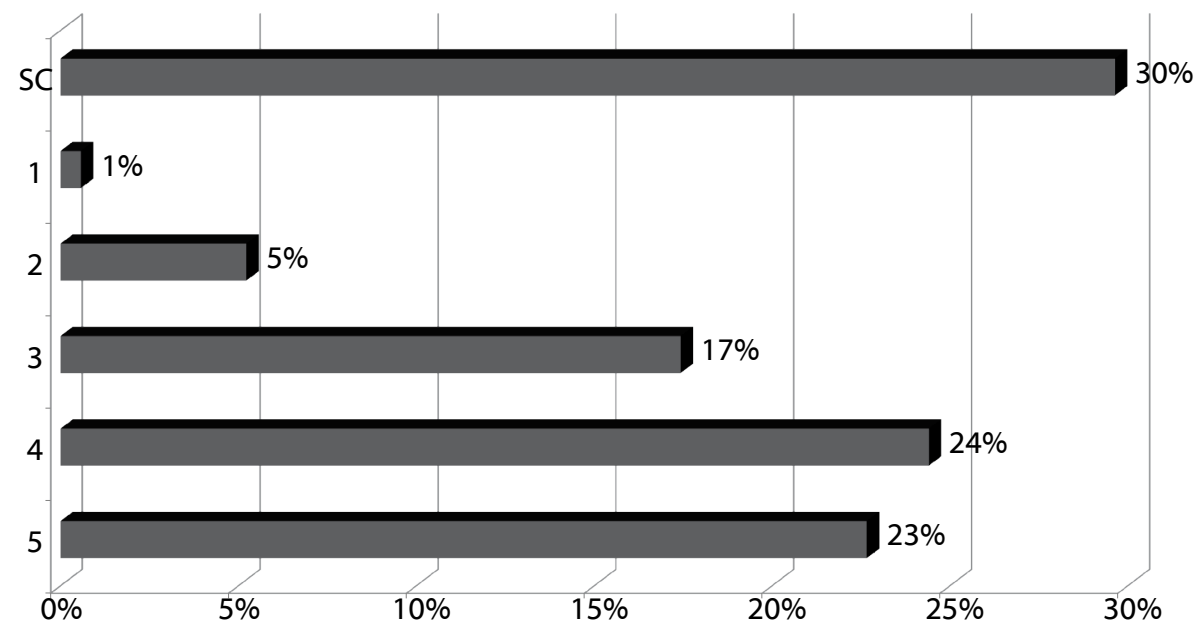

ENADE 2009 - IES

Universidades Privadas

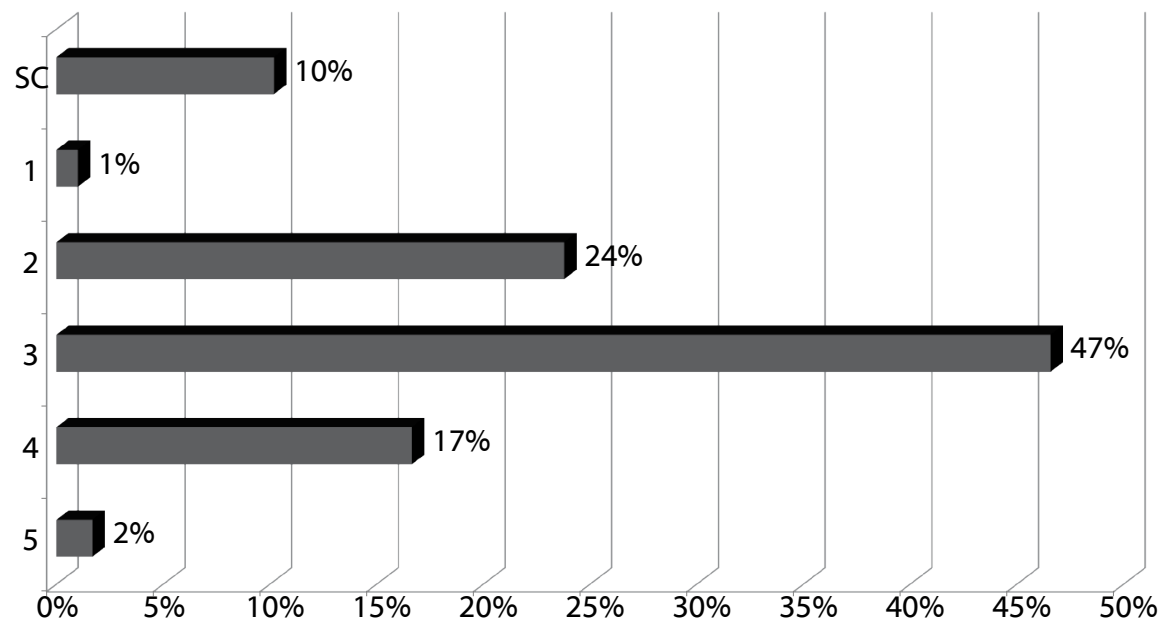


Quando a leitura dos dados se dá pelo número de estudantes, no entanto, os números pouco variam nas IEs privadas, cujo impacto passa de $19 \%$ para 21\% no nível satisfatório. Já nas IEs públicas, as representações melhoram consideravelmente, de modo que $67 \%$ dos estudantes de iEs estariam acima do referencial mínimo de qualidade, sendo $37 \%$ no nível de excelência e $30 \%$ no nível bom, contra $47 \%$ de IEs, sendo $23 \%$ em nível de excelência e $24 \%$ em nível bom. A comparar estes dados com o universo do qual foram retirados, esta situação pressupõe admitir que, se os melhores estudantes tanto de IES públicas quanto de particulares estão estudando em universidades, os estudantes das IEs públicas conseguem produzir resultados ainda melhores, visto que $77 \%$ dos estudantes da rede privada não apresentam sequer um nível considerado bom. Pelo contrário, $26 \%$ deste montante sequer atingiram um nível satisfatório. 
Gráfico 6 Resultados por estudantes em universidades públicas e privadas

ENADE 2009- estudantes inscritos

Universidades Públicas

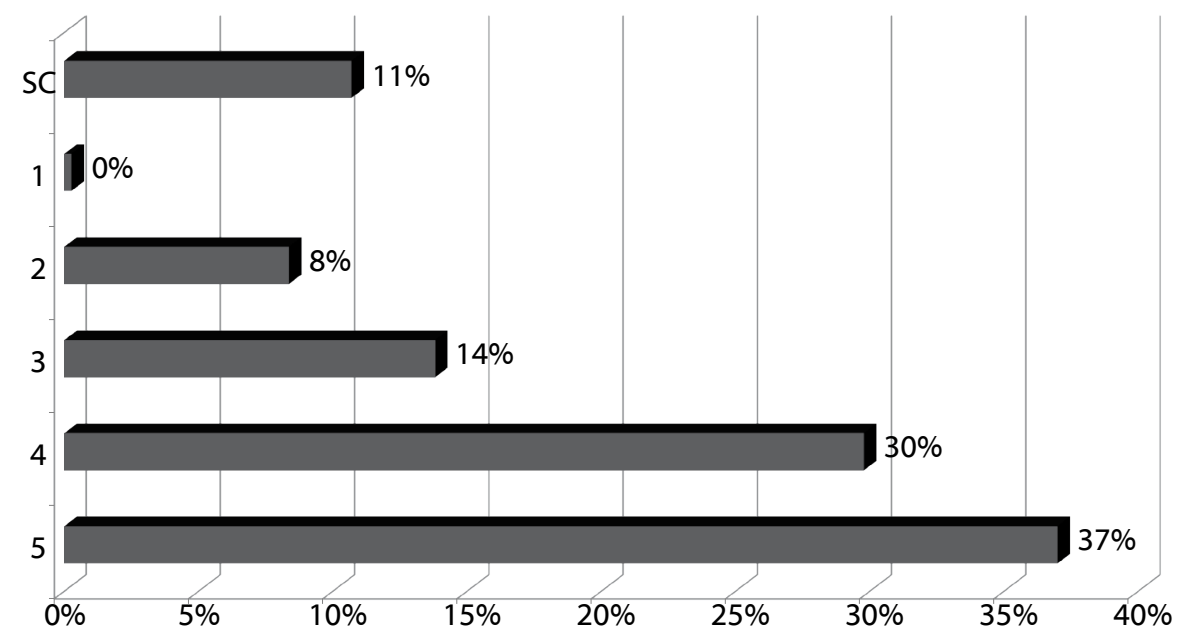

ENADE 2009 - estudantes inscritos

Universidades Privadas

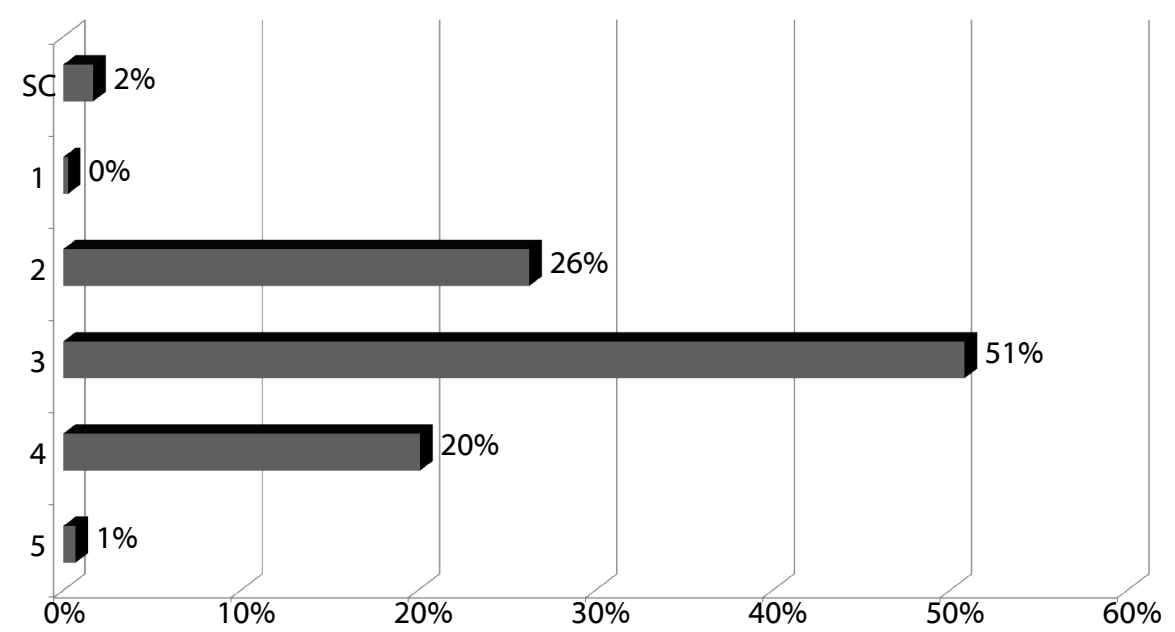




\section{DIFERENCIANDO OS RESULTADOS POR CENTROS UNIVERSITÁRIOS}

A leitura dos resultados dos centros universitários foi prejudicada pela pequena amostra deste tipo de instituição quando pública: somente sete instituições constaram nos microdados, o que inviabiliza uma análise estatística confiável. Os dados serão somente apresentados, neste caso.

Quando se fala dos centros universitários privados, no entanto, seus I28 representantes já permitem um retrato confiável, mas não favorável, conforme o Gráfico 7. Embora dois terços dos avaliados tenham conseguido atingir o referencial mínimo de qualidade, apenas $9 \%$ dos centros universitários privados atingiram as notas 4 e 5 , sendo somente $2 \%$ no nível de excelência, percentual semelhante ao número de estudantes avaliados com o mesmo conceito. Assim, percebe-se, com tristeza, que, mesmo liberta das regulamentações que muito exigem das universidades, mas preservando quase toda a sua autonomia, que poderia ser usada a favor da excelência no ensino, depara-se com uma realidade semelhante à das faculdades privadas, onde Io\% dos estudantes estão entre os níveis bom e excelente, estando somente $3 \%$ neste último nível (Gráfico Io). 
Gráfico 7 Resultados por centros universitários públicos e privados

ENADE 2009 - IES

Centros Universitários Públicos

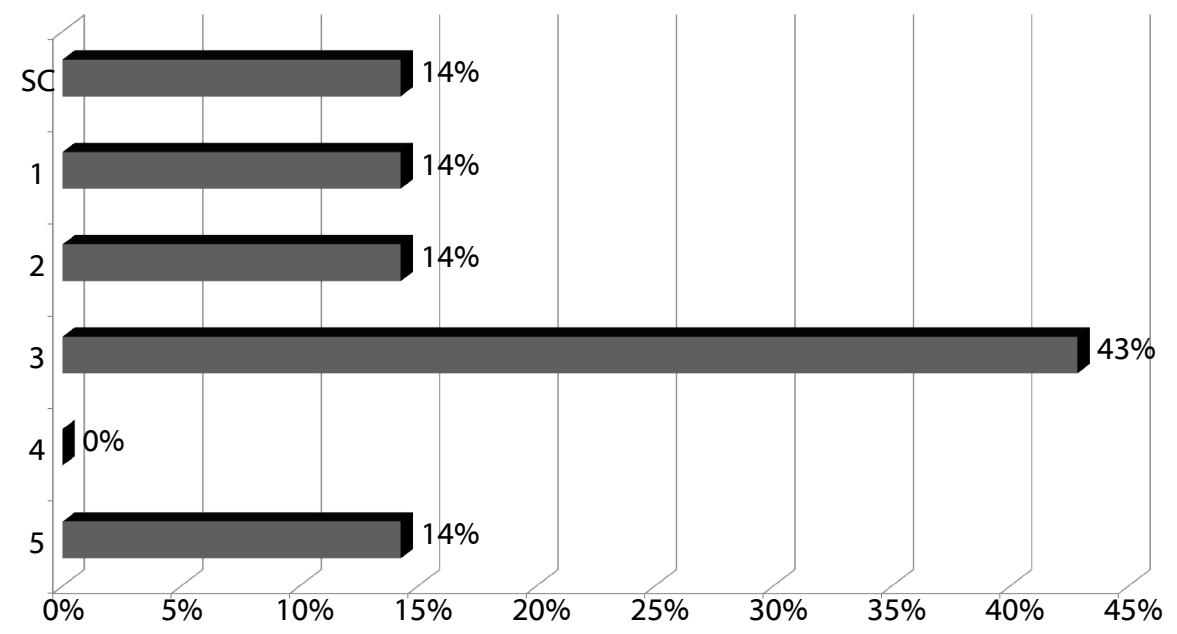

ENADE 2009 - IES

Centros Universitários Privados

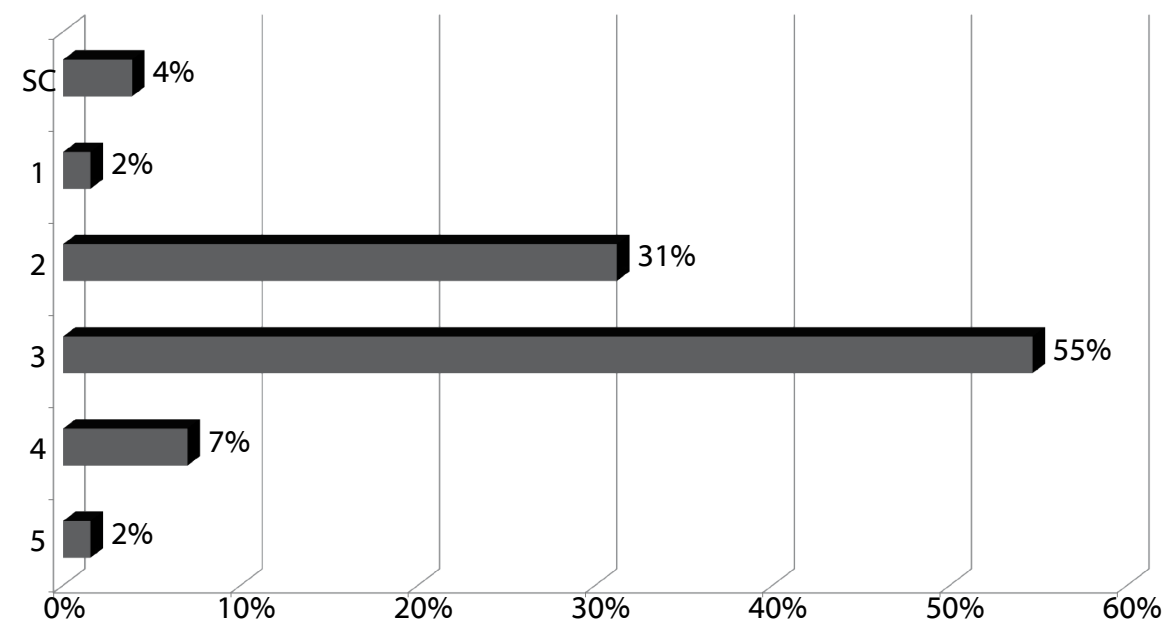


Não obstante, um resultado chama ainda mais a atenção. Considerando a rede privada, ao se mudar a referência de número de IEs para o número de estudantes inscritos no Enade, a representação daqueles que sequer alcançaram o referencial mínimo da qualidade passa de $33 \%$ para $44 \%$. Este resultado chega a ser alarmante, considerando que a autonomia proposta aos centros universitários derivaria da expectativa da concentração de esforços na excelência de ensino. No entanto, o que se vê é a formação de profissionais que chegam despreparados ao mercado. 
Gráfico 8 Resultados por estudantes em centros universitários públicos e privados

ENADE 2009 - estudantes inscritos

Centros Universitários Públicos

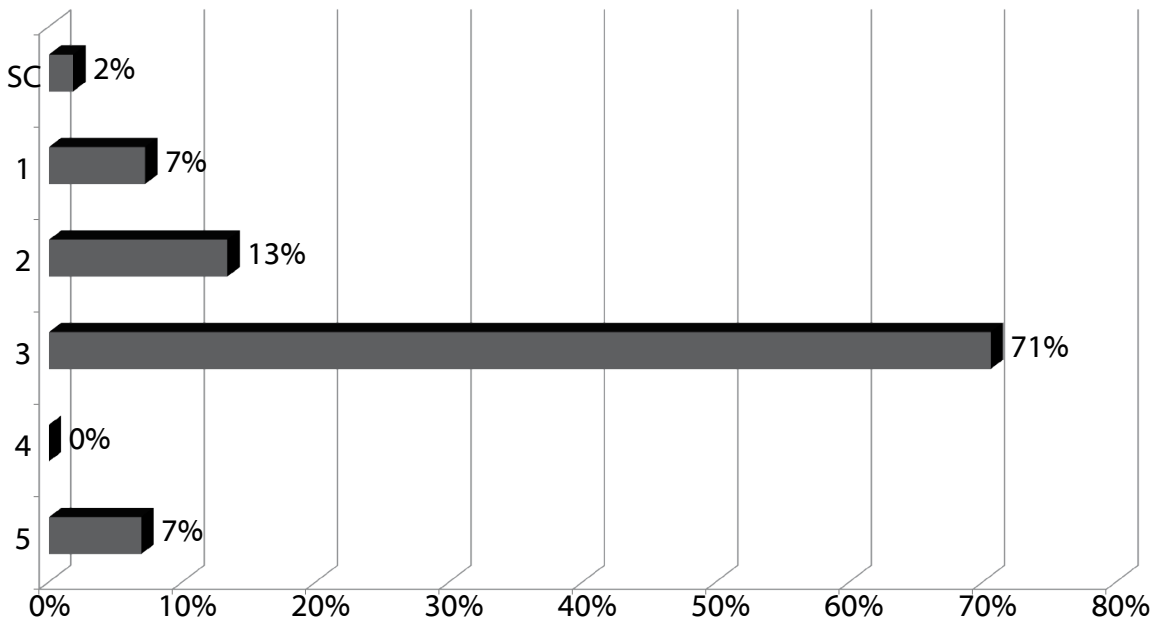

ENADE 2009 - estudantes inscritos

Centros Universitários Privados

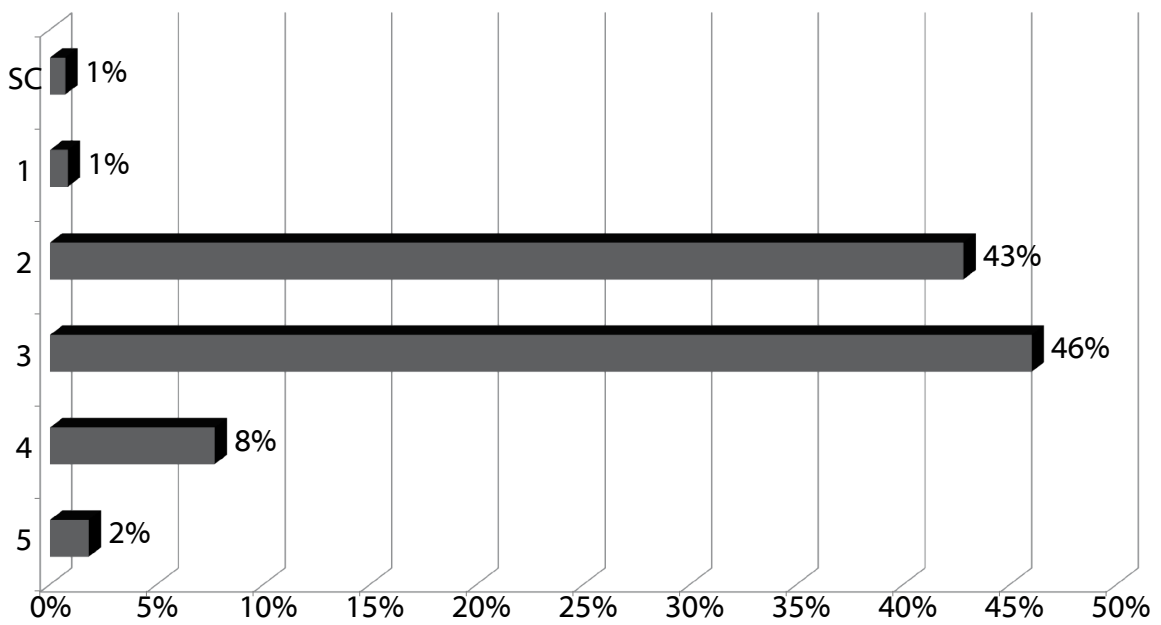




\section{DIFERENCIANDO OS RESULTADOS POR FACULDADES PÚBLICAS E} PRIVADAS

A realidade das faculdades é curiosa. Embora as IEs públicas demonstrem uma pequena superioridade em relação às IEs privadas, não se pode desconsiderar o número de IEs envolvidas no cálculo. Enquanto a rede pública é representada por 3I instituições, a rede privada tem 33 vezes mais faculdades e 38 vezes mais estudantes, ou seja, um contingente de II6.7I3 pessoas que iniciam a profissão todo ano. Portanto, a prevalência do conceito 2 no caso privado deve ser encarada com preocupação maior que nas faculdades públicas, na medida em que seu impacto no ambiente será bem maior. 
Gráfico 9 Resultados por faculdades públicas e privadas

ENADE 2009 - IES

Faculdades Públicas

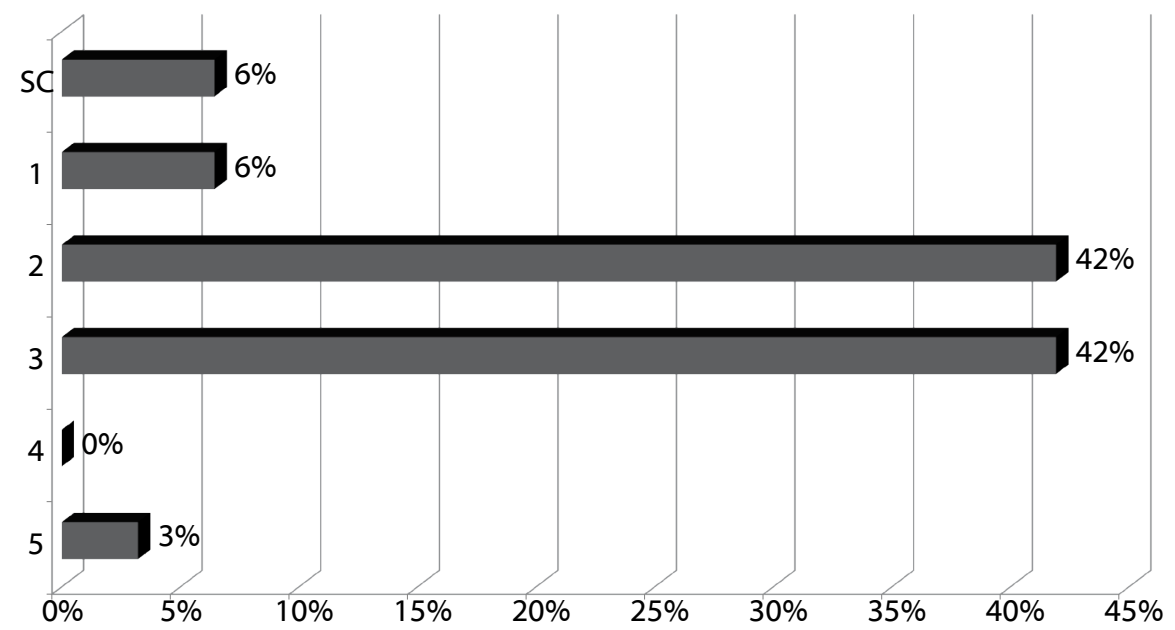

ENADE 2009 - IES

Faculdades Privadas

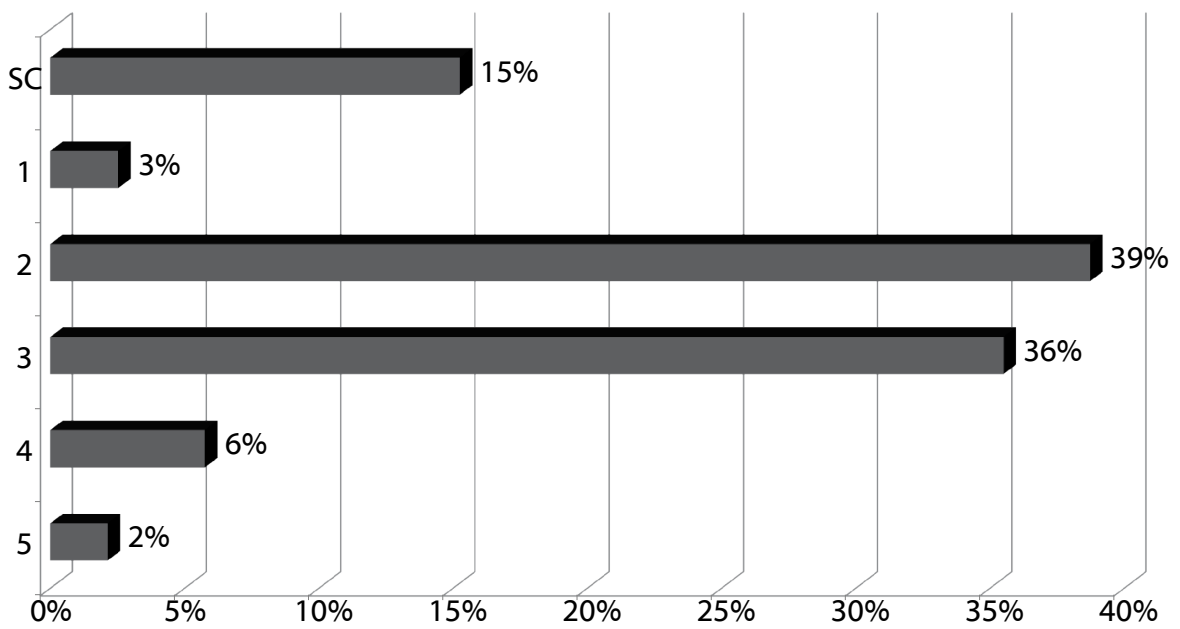


As faculdades públicas aqui apresentadas não têm necessariamente relação com o sistema federal de ensino superior. São geralmente fundações de direito público, principalmente municipais, que não desempenham um trabalho adequado, pois $48 \%$ ( $42 \%$ com nota 2 e $6 \%$ com nota i) delas se encontram abaixo do referencial mínimo de qualidade e somente $3 \%$ delas podem ser classificadas como de excelência, de acordo com o Gráfico 9.

As faculdades privadas, por sua vez, conseguem classificar I0\% dos seus estudantes na faixa superior, sendo $3 \%$ ótimos e $7 \%$ bons, apesar de $44 \%$ figurarem como ruins ou péssimos. Tal distribuição só é possível porque existem várias instituições privadas de expressão regional ou reconhecidas nesta área de conhecimento, ao mesmo tempo em que este tipo de IES também é o primeiro passo de muitos empreendedores sem experiência na área de educação. 
Gráfico 10 Resultados por estudantes em faculdades públicas e privadas

ENADE 2009 - estudantes inscritos

Faculdades Públicas

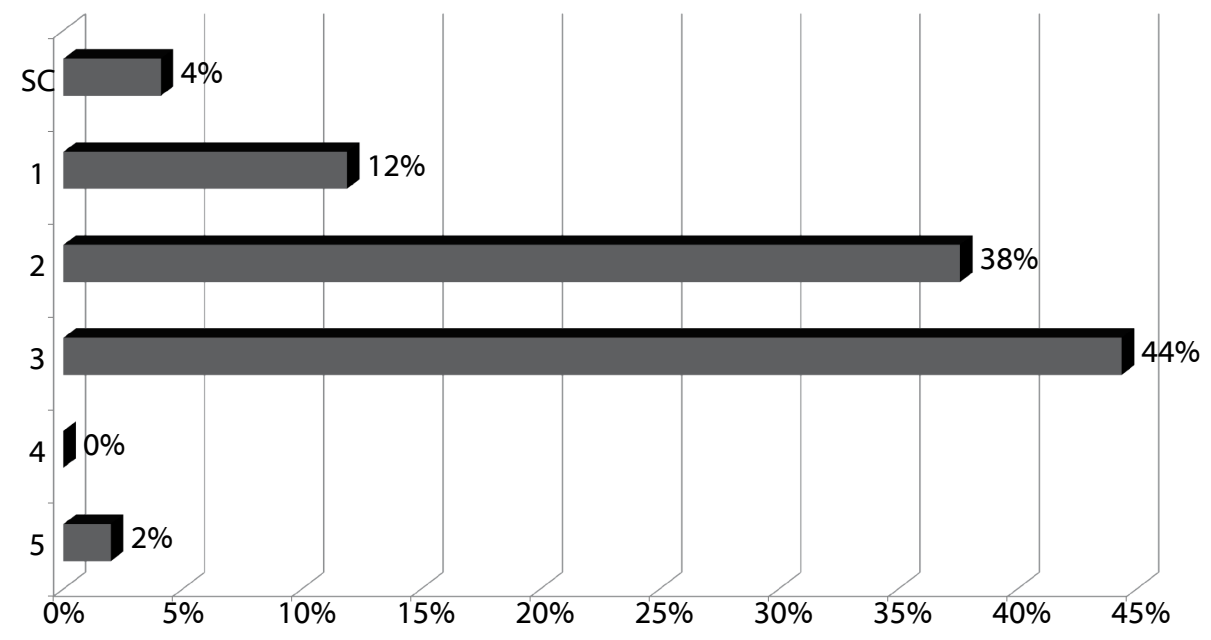

ENADE 2009 - estudantes inscritos

Faculdades Privadas

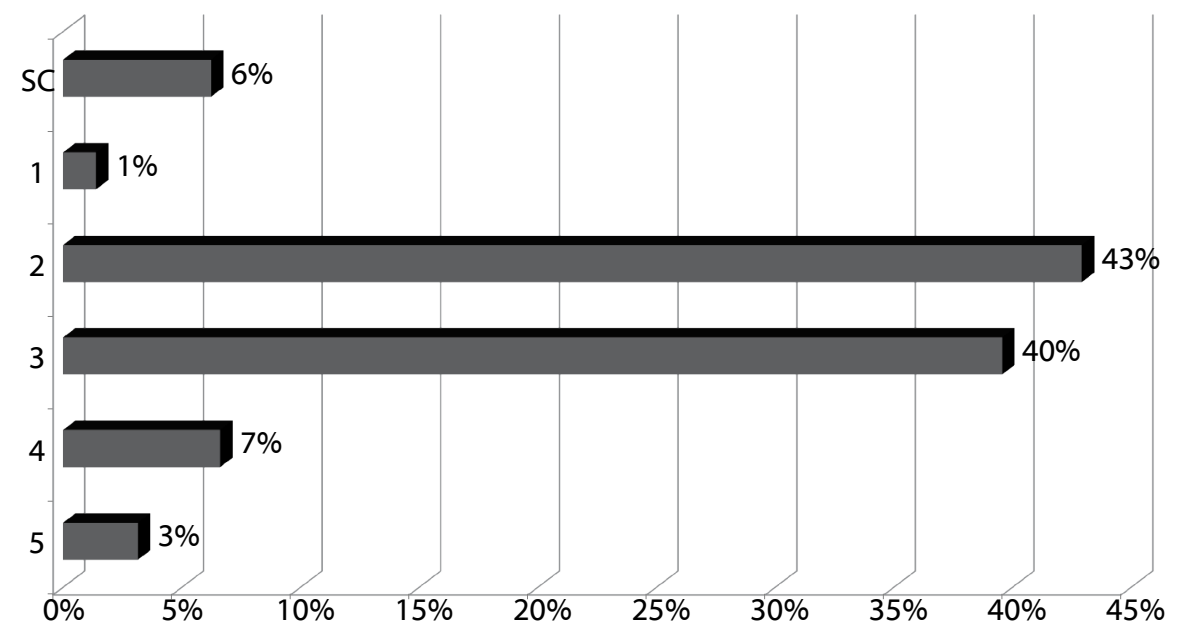




\section{CONSIDERAÇÕES FINAIS}

Parece não haver mais dúvidas quanto à necessidade de avaliar a educação oferecida no país. É necessário contar com profissionais cientificamente competentes para que haja o desenvolvimento nacional. Contudo, constatase ser esta uma cultura ainda em construção no país, a julgar não só pelo desconforto das IEs ao serem avaliadas, mas pela própria escassez de artigos disponíveis nas bases de dados produzidos pela comunidade científica nacional sobre o tema.

O processo avaliativo, no entanto, não pode ser mero construtor de rankings, sob pena de apenas quantificar o que foi aprendido. Mais que a mensuração da sua eficiência, o resultado da avaliação deve apontar onde estão as lacunas de formação dos estudantes avaliados ao final de curso, apontando problemas nas relações socioeducativas, que deveriam garantir profissionais de alto nível social e científico.

Desta forma, é importante registrar a evolução do sistema avaliativo que, partindo de uma base construída no governo FHC, se tornou mais complexo ao constituir no governo Lula o Sinaes, que se utiliza da Avaliação Institucional, da Avaliação das Condições de Ensino (ACE) e do Exame Nacional de Desempenho dos Estudantes (ENADE), entre outros, para construir uma visão mais abrangente dos resultados obtidos. Mais que a mera aferição de conhecimentos, o sistema procura avaliar a formação de indivíduos competentes, em acordo com as políticas públicas para o setor, ainda que todo o conjunto de leis e portarias continue confundindo habilidades e competências.

Entre os êxitos desta evolução, pode-se citar a criação do IDD, que se propõe a mensurar o valor que as IEs conseguiram agregar à formação dos estudantes na checagem com outras IES comparáveis, segundo critérios já mencionados anteriormente. Desta forma, busca-se eliminar o desequilíbrio inicial causado pela captação de estudantes de níveis muito diferentes por IEs públicas e privadas, pois o IDD consegue descentralizar o foco na nota do Enade, tornando a constituição de rankings e classificações menos significativas. 
É importante ressaltar que desta forma o Sinaes se inscreve em uma compreensão mais ampla de avaliação das IEs como um todo. A prova não é substancialmente diferente do Provão, mas ela é parte da avaliação do processo de aprendizagem e seus resultados, combinados às outras dimensões previstas no Sinaes. Pretende-se, assim, tornar o processo avaliativo mais rico e multifacetado, sem abandonar a tentativa de quantificação dos resultados, característicos do INEP, que levaram recentemente à proposição de cálculos agregadores como o CPC e o IGC.

Quando se trata do embate entre os sistemas de educação público e privado, há que se desmistificar, no caso dos cursos de administração, a ideia de que o ensino superior público é obrigatoriamente de qualidade. Em primeiro lugar, porque há muitas IEs públicas que não atingem o referencial de qualidade mínimo apontado pelo inep. Depois, porque os dados apontam apenas as universidades públicas como espaços de ensino dignos de nota. Centros universitários e faculdades públicas não apresentaram bons resultados, sejam absolutos ou na comparação com seus congêneres privados. Ou seja, o poder público como mantenedor, em qualquer nível, deve se preocupar mais com a qualidade oferecida por estes cursos.

A decisão neste artigo de analisar os resultados pelo quantitativo de IES e de estudantes se provou bastante acertada, pois muda a visão sobre o impacto dos tipos de IEs na formação de novos profissionais. Assim, ainda que as faculdades tenham se revelado, em grande parte, ineficazes em suas propostas de formação, o impacto desta notícia diminui quando se sabe que, apesar de representarem dois terços do número de IEs registradas, elas significam pouco mais da metade do número de estudantes matriculados no país. É uma notícia na mesma linha do impacto das universidades, que se verificou o melhor tipo de IES da pesquisa, que representa $28 \%$ do total das IES, mas $38 \%$ do corpo discente. Os centros universitários, da mesma forma, ampliam seu impacto de $8 \%$ do número de IEs para $13 \%$ do total de estudantes.

No cômputo geral, fica patente que analisar o quantitativo de estudantes contra o de IES mostra o verdadeiro impacto da performance das escolas e deixaria o quadro um pouco menos aflitivo, caso pudessem ser esquecidos 
os números absolutos: ainda estão registradas 560 IEs com desempenho sofrível, que estão formando $85 \mathrm{mil}$ administradores por ano.

As universidades e centros universitários devem aumentar paulatinamente sua importância e representatividade no número de formandos no decorrer dos anos que se seguem. Primeiro, por sua própria natureza: eles tendem a se expandir mais facilmente, uma vez que têm autonomia para abrir novos cursos, especialmente aqueles que quase não apresentam restrições econômicas ou reguladoras por parte dos seus conselhos profissionais, como o curso de Administração. Segundo, por conta da notoriedade regional que instituições desta natureza ganham na medida em que abrem mais cursos: as escolas tendem a se tornar mais atrativas quanto mais sólidas se apresentam aos futuros estudantes; terceiro, por imposição de uma situação mercadológica: a consolidação da indústria da educação superior é uma realidade em todos as regiões do país, com fusões e aquisições que aumentam o poder econômico dos grupos consolidadores e torna a vida mais difícil para as faculdades remanescentes.

Seria bom que a expansão do número de estudantes se desse preferencialmente em centros universitários e principalmente universidades, pois ficou provado pelo estudo que estas formas de IES alcançam resultados superiores no processo avaliativo. Há que se estudar, no futuro, a correlação com as exigências estipuladas pelo MEC para estes tipos de IES, como número de mestres e doutores, maior dedicação dos professores e, no caso das universidades, a exigência de programas de pós-graduação, para que se verifique a influência destes fatores no maior sucesso dos seus estudantes no Enade. Outra linha possível de investigação é realizar a mesma pesquisa levando-se em conta somente o IDD, a fim de verificar quais tipos de IES, sob que vinculações administrativas, são as que conseguem agregar mais valor no processo educativo.

Finalmente, analisados tanto por número de IES como por estudantes, os resultados mostraram que universidades são bem melhores que centros universitários e estes são ainda melhores que as faculdades isoladas, que instituições públicas não são sempre as melhores e que o crescimento do número de estudantes em universidades e centros universitários particulares 
promete impactos positivos em termos de desempenho dos egressos no mercado de trabalho. E que o senso comum, em parte, prevalece: os melhores profissionais, em geral, continuam saindo das universidades públicas. 


\section{REFERÊNCIAS}

BITTENCOURT, H. R.; VIALI, L.; CASARTELLI, A. de O.; RODRIGUES, A. de O. Uma análise da relação entre os conceitos Enade e IDD. Estudos em Avaliação Educacional. São Paulo, v.19, n.40, p.247-262, 2008.

BRASIL, Ministério da Educação e do Desporto. Decreto n 2.026, de 10 de outubro de 1996. Brasília, D.O., 1996.

Lei no 10.861, de 14 de abril de 2004. Brasília, D.O., 2004.

Portaria Normativa 4, de 5 de agosto de 2008. Brasília, D.O., 2008.

Portaria Normativa 12, de 5 de setembro de 2008. Brasília, D.O., 2008.

CEEAD - Comissão de especialistas de ensino de administração da SESu/MEC.

Biblioteca básica para os cursos de graduação em administração. Florianópolis: UDESC, 1997.

ECO, U. Como se faz uma tese. 14. ed. São Paulo: Perspectiva, 1977.

INEP. Censo da Educação Superior. 2009. Microdados para download. Disponível em: $<$ http://portal.inep.gov.br/basica-levantamentos-acessar>. Acesso em: 25/10/2011.

MARINHO-ARAUJO, C. M. O desenvolvimento de competências no Enade: a mediação da avaliação nos processos de desenvolvimento psicológico e profissional. Avaliação: Revista da Rede de Avaliação Institucional da Educação Superior, v.9, n.4, 2004.

MARTINS, G. de A.; THEÓPHILO, C.R. Metodologia da investigação científica para ciências sociais aplicadas. 2.ed. São Paulo: Atlas, 2009.

ROTHEN, J. C.; NASCIUTTI, F. A educação superior em prova: o perfil da educação superior apresentado pelos resultados do Enade 2005 e 2006. Revista Diálogos Educacionais, v.11, n.32, 2011.

SESU - Secretaria de Educação Superior. Portaria n 11, de 28 de abril de 2003. Brasília, D.O., 2003.

SINAES. Sistema Nacional de Avaliação da Educação Superior (SINAES): Bases para uma Nova proposta da Educação Superior. ago. 2003. Disponível em: $<$ http://www.unifesp. $\mathrm{br} / \mathrm{rei}$ toria/orgaos/comissoes/avaliacao/sinaes.pdf $>$. Acesso em: 20/03/2012.

SOBRINHO, J.D. Educação e avaliação: técnica e ética. In: SOBRINHO, J.D.; RISTOFF, D.I. (Org.). Avaliação Democrática para uma Universidade Cidadã. Avaliação Democrática para uma Universidade Cidadã. Florianópolis: Insular, 2002.

VERGARA, S.C. Projetos e relatórios de pesquisa em administração. 13.ed. São Paulo: Atlas, 2011.

VERHINE, R.E.; DANTAS, L.M.V.; SOARES, J.F. Do Provão ao ENADE: Uma análise comparativa dos exames nacionais utilizados no Ensino Superior Brasileiro. Ensaio: Avaliação e Políticas Públicas em Educação, v.14, n.52, p. 291-310, 2006 


\title{
DADOS DOS AUTORES
}

\author{
ALEXANDRE MENDES NICOLINI^ alexandre.nicolini@unigranrio.com.br \\ Doutor em Administração pela UFBA \\ Instituição de vinculação: Universidade do Grande Rio \\ Rio de Janeiro/RJ - Brasil \\ Áreas de interesse em pesquisa: Inter-relações da aprendizagem individual, social, \\ teórica e prática. \\ * Rua da Lapa 86 Lapa Rio de Janeiro/RJ 2002I-I80
}

RUI OTÁVIO BERNARDES DE ANDRADE ruiotavio@unigranrio.com.br Doutor em Engenharia da Produção pela UFSC

Instituição de vinculação: Universidade do Grande Rio

Rio de Janeiro/RJ - Brasil

Áreas de interesse em pesquisa: Gestão Educacional, Desenvolvimento Organizacional

e Marketing.

ADRIANA AMADEU GARCIA TORRES adriana.amadeu.garcia@gmail.com Mestre em Administração pela EBAPE/FGV

Instituição de vinculação: Universidade do Grande Rio

Rio de Janeiro/RJ - Brasil

Áreas de interesse em pesquisa: Estudos em organizações e Pessoas. 